\title{
EREC, EL CABALLERO CORTESANO QUE APRENDIÓ A AMAR
}

\author{
Marta E. Montero Navarro \\ Universidad de Sevilla
}

\begin{abstract}
The theme of Love appeared first in Germany with the chivallrous literature in the 12 th. century. The first novel of this genre, that is Hartmann's von Aue Erec, reflected the new sensibility that brought the chivallrous culture and left the religious sensibility that predominated for centuries. These writers were interested in the world of human emotions and material needs.

This article will consider on Love in Hartmann's von Aue Erec, but from a new point of view. Here the male character is the focus of attention. The process of Erec falling in love with lady Enite is actually the main subjet. His arrogance and manliness -that reminds one of the old Germanic code- , his responsibility as a knight, his strong desire for revenge ...the courtly and chivallrous conventions, in a word, act as a hindrance to him. He does not realise until the end of the novel that another world exists; a world compatible with the social sphere of honour and bravery: that of love, sensibility and comradeship that lady Enite tries to show him.
\end{abstract}

Ese distanciamiento generalizado que mantiene la literatura cortesano-caballeresca respecto a la situación social del momento, esa actitud escapista que adopta, en definitiva, ante la realidad histórica, es lo que la hace atractiva y fascinante. La vida representada en los textos de las novelas artúricas contrasta con un devenir histórico sumido en el atraso, las incomodidades y las penurias que afectaban a cada estamento (aunque no a todos por igual) ${ }^{1}$. La intención de liberar, por unos instantes, de esa precaria existencia a los receptores de tales narraciones fue probablemente el motor que impulsó la creación de las mismas. Con la transmisión de un modelo social idílico, a imitación del francés, se describía un mundo de ensueño aristocrático en el que damas y caballeros virtuosos hacían las delicias de la corte. Asimismo, un componente moralizante parece subyacer a este conjunto de novelas, cuyo contenido permitía confrontar los ideales de perfección

\footnotetext{
1 "Die düstere Enge auf den Burgen, die unvorstellbare Primitivität der hygienischen Verhältnisse, der Mangel an Licht und Heizung, das Fehlen einer sachkundigen medizinischen Betreuung, die ungesunde Ernährung, die Rohheit der Tischsitten, das entwürdigende Sexualverhalten gegenüber Frauen: das war die Realität (...) Die Dichter haben eine Märchenwelt beschrieben, in der alle politischen, wirtschaftlichen und sozialen Probleme und Konflikte, mit denen die adlige Gesellschaft in der Realität konfrontiert war, künstlich ausgeklammert blieben." En: J. Bumke, Höfische Kultur (München 1987) 9, 381.
} 
cortesanos -encarnados en un mundo artúrico lejano en el tiempo- con esa esencia nobiliaria ruda y primitiva de su presente. Se perseguía impulsar, así, la asunción de una existencia moralmente perfecta. Aun con el convencimiento de que dichos autores hubiesen escrito sus obras con tal finalidad, resulta difícil comprobar si los ideales contenidos en este tipo de literatura fueron asimilados y puestos en práctica por el estrato superior de la sociedad, en este caso alemana. Parece más convincente pensar, que la extraordinaria acogida de esta tendencia literaria por parte de la nobleza teutona estuvo motivada por el interés de ésta en asimilar el estilo de vida francés tras ver reflejados en aquellos textos sus tiempos dorados, muy alejados del caos interno existente en el mundo que habitaban ${ }^{2}$. Sin embargo, al atraso y a la tosquedad reinantes en la sociedad de aquellos siglos hay que oponer una revolución literaria sin precedentes. Con ella se inicia el desmarque paulatino de una tendencia temática religiosa que fue predominante en tiempos pretéritos. Es ahora cuando la subjetividad, el mundo de los sentimientos y la sensibilidad, irrumpe con fuerza.

Es por todos conocida la dificultad que entraña poder determinar el grado de subjetividad presente en la literatura cortesano-caballeresca. Y ello debido a que gran parte del contenido que en ella se oculta, no es más que la exposición de un conjunto de normas y convenciones sociales idealizadas ${ }^{3}$, que nada tiene que ver ni con la realidad, ni con experiencias y sentimientos individuales del creador. Sin embargo el autor, el hombre, no puede escribir soterrando su propio interior, y aunque no pretenda manifestar de forma consciente un particular subjetivismo, su creación expresará algún tipo de gusto, preferencia o visión personal relacionadas con determinados aspectos de la existencia como puede ser por ejemplo el sentimiento amoroso, centro de esta investigación-. Es decir, aunque a las novelas artúricas les une una cierta similitud temática ${ }^{4}$, siempre habrá algún elemento diferenciador en la estructura más profunda de la obra que se contraponga a las influencias sociales o literarias del momento.

Como ya se ha mencionado en líneas anteriores, a través de este conjunto de textos -a los que pertenece la narración cuyos protagonistas aquí se analizan-, se intuye la presencia de un nuevo ser humano interesado en abordar cuestiones relacionadas con el mundo sensible del Hombre. En estos mismos escritos se expone el progresivo desarrollo del individuo, de una sociedad en definitiva, que comienza a elaborar textos de contenido profano y se va apartando de los modelos netamente religiosos del período anterior. Entre otros temas se descubre el amor, cuyo tratamiento -muy variado según los géneros e

\footnotetext{
2 “Die Jahrzehnte, in denen die höfische Dichtung ihre höchste Blüte erlebte, waren in Deutschland eine besonders schlimme Zeit innerer Kriege und öffentlicher Wirren. Der Tod Kaiser Heinrichs VI. Im Jahr 1197 hat das Land in einen Zustand der Anarchie gestürzt." En: J. Bumke, op.cit., 11.

3 "Nach der Schilderung der Dichter erhielt der ganze höfische Gesellschaftsbetrieb mit seinem materiellen Prunk und seinen zeremoniellen Umgangsformen überhaupt erst seinen Sinn, wenn man ihn auf das Ideal der Courtoisie, der höfischen Vollkommenheit, bezog, (...)" En: J. Bumke, op.cit., 381.

4 "Das Schema eines Artus-Aventiurenromanes ist hier durchgeführt: Ausritt - Gewinnung der Geliebten ehrenvolle Rückkehr. Man stattet Hin- und Rückweg mit einer Reihe gefährlicher Abenteuer aus, und das Schema gediehe zum ausgewachsenen Roman." En: H. De Boor, Geschichte der deutschen Literatur. Band II (München 1979) 67.
} 
incluso dentro de cada uno de ellos- va a ser la tónica dominante de esta cultura literaria. El concepto de amor es imposible definirlo fuera del ámbito ficcional. Es la propia creación, la única fuente más cercana que se posee para conocer la reacción de aquellos hombres y mujeres ante el citado sentimiento, considerado el valor más importante de la sociedad cortesana por ser aglutinador de innumerables virtudes ${ }^{5}$. A este respecto, sin embargo, no se debe olvidar hacer una breve mención a los tratados elaborados por los teólogos concernientes al tema amoroso. En ellos dejaban entrever una rígida e intransigente postura -de la que era víctima el sexo femenino-, que contrastaba con aquella expuesta por intelectuales laicos, partidarios unos de la sumisión y el servicio amoroso a la dama, mientras otros abogaban por un amor más real e igualitario -como el experimentado por los protagonistas que intervienen en la obra objeto de este análisis-.

Erec, ${ }^{6}$ así se llama el caballero que va a ser aleccionado en el amor; Enite, su esposa, se convierte en su guía e instructora de forma altruista y desinteresada, dejando fluir generosamente una autenticidad y transparencia plenas. El halo misterioso que configura y caracteriza sobremanera al personaje de Enite se debe principalmente a esa dualidad que envuelve todo su ser: a los rasgos convencionales de su actuación en un plano superficial, hay que contraponer el significado que subyace a los mismos, a un nivel más profundo. La hermosa Enite es, a primera vista y desde el comienzo del relato, la fiel imagen de la mujer medieval sometida y entregada a su compañero, tal y como revela su particular manera de exteriorizar el sentimiento amoroso. Su reacción, observada en los primeros momentos de la narración, cuando presencia el combate entre Erec y su oponente Ider, se hace difícilmente comprensible. Con su y lamento expresa abiertamente una extraordinaria preocupación por un hombre apenas conocido, que además acaba de separarla de su hogar con el fin de obtener un beneficio personal, que no era sino restaurar su honor? ${ }^{7}$. Este temor que manifiesta de forma tan sincera y humana por la vida de su futuro marido, está relacionado con la extrema belleza de la dama; un temor que estaría justificado, pues, teniendo en consideración el concepto de belleza medieval, por el cual la hermosura externa reflejaba siempre la belleza interior, la bondad del individuo ${ }^{8}$. De aquí se puede deducir, que la congoja de esta mujer no está ocasionada por el miedo a sufrir la humillación que supondría la derrota de su caballero, sino que la doncella se deja dominar por un sentimiento puro e inocente; por un amor que irrumpe en su vida de forma instantánea, manifestándose irracional, precipitada e impulsivamente. Con dicho comportamiento se

5 " > 0 was für eine wunderbare Sache ist die Liebe, die den Menschen in so vielen Tugenden erstrahlen lässt und ihn eine solche Fülle edler Sitten lehrt.< In diesen Punkt gab es keine Meinungsverschiedenheiten zwischen Andreas Capellanus und den höfischen Dichtern. Die Liebe, vor deren Gefahren sie eben noch gewarnt hatten, wurde von ihnen als höchster irdischer Wert und Quelle alles Guten verherrlicht." En: J. Bumke, op.cit., 522.

${ }^{6}$ Hartman von Aue: Erec (Tübingen 1967)

7 "Erec braucht die Frau, um sein erstes Abenteuer zu bestehen und seine Ehre wiederzugewinnen." En: E. Carne, Die Frauengestalten bei Hartmann von Aue (Marburg 1970) 35.

8 "Dass die menschliche Schönheit von Gott geschaffen war, konnten die Dichter von den Theologen lernen; und (...) dass die Schönheit des Menschen als ein Spiegel seiner inneren Vollkommenheit angesehen werden kann. Für die scholastische Ästhetik war Schönheit die Anschaubarkeit des Wahren und Guten." En: J. Bumke, op.cit., 423. 
confirma el profundo sufrimiento de una mujer, que resulta de su falta de indiferencia ante los acontecimientos presenciados; dolor originado tamabién, por esa capacidad de amar infinita. Esta preocupación que manifiesta sin reservas por su compañero en la mencionada escena, va a ser incesante en todas sus intervenciones posteriores. Con tal actitud, esta mujer se erige en representante de esa parte de la Humanidad que no tiene reparos en exteriorizar ante el resto de la sociedad -simbolizada aquí por todos los asistentes al combate-, esa sensibilidad que nace del sentimiento amoroso. Su conducta amorosa irracional responde al ideal de mujer-esposa de aquel entonces. En él se afirmaba que ésta amaba a su compañero de forma errónea al dejarse llevar por los sentimientos, siendo incapaz de controlar su parcela afectiva como era propio de su contrario, el cual amaba con juicio, anteponiendo la razón al afecto ${ }^{9} \mathrm{~A}$ pesar de dichas aseveraciones teológicas, el autor de la obra objeto del análisis, Hartmann von Aue, no parece condenar el desbordamiento emocional de la protagonista -por otra parte constante a lo largo de la novela-, pues nunca realiza una valoración negativa acerca del mismo.

La cualidad principal de Enite es esa capacidad de entrega que posee desde su primera aparición, y por la que no exige nada a cambio. También el calificativo de "ir lieben man" $\left(\right.$ v.1384) ${ }^{10}$-inconcebible debido al poco tiempo transcurrido desde que se conocieronconfirma su extrema generosidad. Además, el narrador parece anular la personalidad de esta joven que pone al servicio del amado para conseguir transformarlo en su faceta personal-espiritual; una aparente falta de identidad propia que facilita ese grado excepcional de enamoramiento, a través del cual se consigue la fusión con el amado. De Enite se sabe poco. Su carácter pasivo le hace pasar desapercibida, y sin embargo, su presencia adquiere una importancia capital, por ser el motor principal en el proceso de aprendizaje de Erec en el sentir amoroso. Enite no cumple simplemente con el imperativo religioso medieval donde "a la mujer correspondía ante todo la obligación de amar al marido"11 - que implicaba obediencia y sumisión-, sino que también siente pura y verdaderamente, siendo esto la causa del largo peregrinaje que emprenderá con su pareja, así como de su amarga existencia durante el mismo.

La delicadeza y ternura patente en estos primeros momentos de la existencia literaria de Enite, contrasta con el carácter materialista del Erec primigenio, el cual irá evolucionando hasta llegar a descubrir sus verdaderos sentimientos por esta dama. Frente a la dulzura y al espíritu sacrificado y cristiano ${ }^{12}$ de la protagonista, se sitúa lo opuesto, el caballero, cuya personalidad parece estar dominada por la dureza y frialdad propias de un guerrero germano. Es éste un personaje que se desenvuelve influenciado por los principios impuestos por esa sociedad cortesano-caballeresca, que le exigirá actuar interesada y

\footnotetext{
${ }^{9}$ En: G. Duby, M. Perrot, Historia de mujeres (Madrid 1992) 140.

10 "ihres geliebten Mannes," La traducción al alemán moderno tomada siempre de: Hartmann von Aue: Erec (Frankfurt am Main 1996)

${ }^{11}$ G. Duby, M. Perrot, op.cit., 139.

12 "Ihre Gedanken sind nur auf sein Wohl gerichtet, dessen Leben sie über das eigene schätzt (...) Deutlich wird in jedem Selbstgespräch Enites ihre Frömmigkeit, mit der sie sich an Gott wendet, und ihre Opferbereitschaft für den Mann, dem sie glaubt alles zu verdanken." En: E. Carne, op.cit., 91.
} 
egoístamente, con el fin de no desentonar ante el resto de su colectivo. Por tal motivo toma a Enite como compañera, movido por su orgullo y sus ansias de venganza, confiando en su victoria debido a la extraordinaria belleza de esta mujer. No la elige por estar enamorado, sino por esa condición de hombre ambicioso y calculador que ha asumido por ser fiel a unas pautas de comportamiento preestablecidas. Las circunstancias le impiden sentir y sólo es capaz de percibir el aspecto físico (material) de la doncella, sin proponerse llegar a conocer la esencia de la misma ${ }^{13}$. Se describe a un Erec seguro de sí mismo -"des engibe ich iu kein langer zil/wan an die selben hôchzît,/daz sich endet der strît,/ob mir nû iuwer helfe vrumt/daz mir mîn dinc ze heile kumt" (v.571-575)-14 y además independiente, porque ignora aún el significado del amor y la complicidad que éste lleva implícito. Se pone al servicio de unas normas o imperativos ("nosotros"), a los que concede mayor importancia que al "yo" y a su existencia como individuo; normas que no se cuestionan, sino que son reconocidas y llevadas a la práctica. Prevalece la idea de lo comunitario sobre la individualidad, y dicha situación perjudicará la relación personal de ambos protagonistas, como reflejan las vivencias experimentadas durante el peregrinaje.

El Erec de los primeros capítulos es joven e impetuoso, cuyo amor propio ofendido se convertirá en el potente antídoto contra el verdadero amor por su dama. La unión de los protagonistas a comienzos de la novela (reforzada posteriormente con el enlace) recuerda vivamente a la política matrimonial practicada mayoritariamente en el Medievo ${ }^{15}$; una política carente de sentido desde un plano afectivo y muy conveniente para los propios intereses. El noble personaje es consciente de lo que hace y se avergüenza por ello: "Erec wart von der rede rot." (v. 560). Sin embargo no rectifica a tiempo, porque en estos momentos priman en él los imperativos sociales sobre aquellos morales e individuales, y el ejercicio de su función como caballero que lucha por su honor, impide su desarrollo afectivo como persona. El protagonista experimenta un amor inmaduro puesto que ama por necesidad; su sentimiento amoroso madurará cuando necesite verdaderamente por amor, y Erec carece de esa "madurez y cultura espiritual"16 al inicio de la narración.

Poco a poco este joven se deja cautivar por el encanto de la doncella, cuyo llanto y cariño, demostrado posteriormente, permiten dilucidar la razón de su existencia. La influencia que ejerce sobre Erec ya se pone se manifiesto cuando éste, durante el enfrentamiento con Ider, fija su atención en la dama para restaurar sus fuerzas y continuar

\footnotetext{
13 "Es besteht kein Zweifel, dass Erec das Mädchen für schön hält, er weiss aber nicht um ihre Einmaligkeit." En: K. Smits, "Die Schönheit der Frau in Hartmanns ,Erec'” En: Zeitschrift für deutsche Philologie. Band 101, Heft 1 (1982), 5.

14 "Ich lasse Euch nicht länger warten als bis zu dem Fest, dass der Streit ein Ende haben wird, wenn mit Eurer Hilfe meine Angelegenheit gut ausgeht."

15 “Gewiss rekurriert der ,Erec' hierin auf die feudale Heiratspraxis, dergemäss die Ehe primär von materiellem Interese bestimmte Rechtsinstitution ist, wobei die Frau weniger als Rechtspartner denn als Rechtsobjekt des im Regelfall zwischen Bewerber und Brautvater geschlossenen Vertrages fungiert." En: V. Ross, Die Artusepik Hartmanns von Aue (Köln 1983) 11.
}

${ }^{16}$ J. A. Pérez-Rioja, El amor en la literatura (Madrid 1983) 32. 


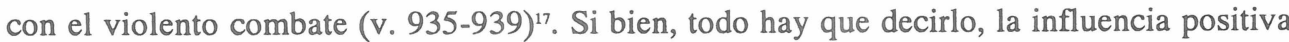
de Enite en estos instantes resulta mínima todavía, puesto que Erec espera conseguir más fortaleza a través de los sentidos, a través de la contemplación de la belleza femenina, es decir, a través de lo material y externo ${ }^{18}$. Además, la mayor fuente de inspiración del caballero para proclamarse vencedor sigue siendo su poderoso deseo de venganza. Es tras la lucha, cuando el protagonista comienza a experimentar la ayuda mutua que debe aprender a valorar y a comprender en su convivencia con Enite. Ésta al recostarle en su regazo demuestra con su ternura ese apoyo incondicional que va a prestar siempre al caballero. Su presencia reporta descanso y consuelo a un Erec cegado y corroído por la ira; una rabia que en estos momentos le impide apreciar el significado de una vida en común y la importancia de la mujer como complemento del hombre en la pareja y por tanto en el amor.

Estando solos y apartados de la civilización por unas horas, brota repentinamente en ambos, la curiosidad y la complicidad (a partir del verso 1484). Este cambio en el comportamiento, sobre todo de Erec, no puede ser más significativo, ya que, durante unos minutos, abandona esa actitud fría y distante. Por primera vez se permite declarar sus sentimientos (v. 1492-94) $)^{19}$, al igual que Enite, intercambiando en silencio miradas recíprocas: "dô wehselten si vil dicke/die vriuntlîchen blicke." (v.1490)20. Pero continúan existiendo diferencias en el grado de sentir amoroso, pues para hacer referencia a su compañera, el narrador emplea un término neutro que no implica un estado de enamoramiento completo - "sine juncvrouwen" (v. 1487) $)^{21}$-. Sin embargo, las connotaciones del calificativo utilizado para hacer constar el estado amoroso de Enite, son muy diferentes y transmiten ese cariño intenso y sincero que le embarga, "ir man" (ihr Geliebte), teniendo en cuenta la naturaleza impositiva de la relación. Se comienzan a establecer los cimientos de un amor -"dâ envant nît noch haz/ze blîbenne dehein vaz:/triuwe und staete si besaz"22 -, institucionalizado y reforzado posteriormente con el sacramento del matrimonio, aceptado por ambos contrayentes ${ }^{23}$; un amor que Erec se atreve a exteriorizar

\footnotetext{
17 "und als er obendrein die schöne Enite ansah, da half ihm dies beim Kampf: denn dadurch verdoppelten sich seine Kräfte."

18 “Symbolisch hat der Dichter das im ,Erec' so dargestellt, dass der durch schoene inspirierte Ritter seine Partnerin während des Kampfes vor Augen haben muss. Nur wer der guoten minne seiner Frau sicher ist, kann sie, wie Erec, ausserhalb des Kampfschauplatzes zurücklassen (...)" En: K. Smits, "Die Schönheit der Frau (...)"., op.cit., 13.

19 "Ihr Herz war voll Liebe, beide gefielen einander gut und immer besser."

20 "Sie wechselten beständig liebreiche Blicke."

21 "seine Braut"

22 "Hass und Feindschaft fanden da keine Bleibe, Liebe und Treue ergriffen Besitz von ihnen."

23 "Es war um die Wende des 12. Jahrhunderts keineswegs selbsverständlich, dass Brautleute von einem Priester getraut wurden. Die Ehe wurde in erster Linie als Kontrakt aufgefasst, entscheidend waren der öffentlich ausgesprochene Konsens der Ehepartner und der Beischlaf." En: K. Smits, "Enite als christliche Ehefrau" En: Interpretation und Edition deutscher Texte des Mittelalters. K. Smits, W. Besch, V. Lange (eds.) (Berlin 1981) 14.
} 
exclusivamente en esa intimidad que le proporciona el campo abierto, la Naturaleza, donde parece liberarse del peso de la sociedad.

Este joven comienza a descubrir sensaciones propiamente humanas como consecuencia de su cada vez mayor admiración e inclinación afectiva hacia Enite. El deseo hace acto de presencia por vez primera (v.1845-1888), poniéndose al servicio de un amor real y natural ${ }^{24}$. A través de ellos se introduce sutilmente el concepto de amor físico; un amor en el que se aúnan por un lado, la pasión -ejemplificada en la condición predadora propia del azor (v.1863)- por otro, la espiritualidad, el cariño y la ternura -cualidades representadas en aquella comparación que alude al amor puro entre madre e hijo (v.1879-84)-. La naturalidad y la sinceridad son los valores predominantes en estas líneas, portadoras a su vez de la nueva sensibilidad que trae consigo la cultura cortesano-caballeresca. En dichos versos hace su aparición un amor igualitario, no subordinado, donde la mujer expone de la misma forma que el hombre, inquietudes y deseos particulares. La compenetración de ambos personajes comienza a ser una realidad, como se desprende de ese anhelo mutuo por un determinado estado o situación. Este deseo que se confesaron antes a través de la mirada y el pensamiento, irrumpe de nuevo aquí, durante su estancia en la corte del rey Arturo; una corte en la que prevalecía -como condición indispensable- un amor casto y cristiano, no así fuera de sus límites. Por esta razón Erec se comporta como un caballero ejemplar, que respeta a su dama y espera hasta la celebración del matrimonio para la consumación del mismo. Es curioso observar también, cómo el protagonista -aunque no públicamente-, muestra su interior participando al mismo tiempo en el núcleo de esa sociedad (la corte artúrica) a la que siempre había prestado una total dedicación, y cuyo efecto inmediato se tradujo en la anulación de la necesidad y la capacidad afectiva de su ser (recordemos al Erec primigenio). En estos momentos, el caballero se está dando cuenta, inconscientemente, de que la pertenencia a este mundo cortesano no es incompatible con el componente subjetivo. La extraordinaria influencia de Enite, "mit schoene und ouch mit güete" (v.1844) ${ }^{25}$, va haciendo posible la instauración del amor en el corazón de su compañero, así como la desinhibición del mismo respecto a sus propios sentimientos, particularmente intensos. No puede resistirse a la atracción que ejerce sobre él la extraordinaria belleza de su dama, ya que ésta irradia una forma de ser desconocida y misteriosa para el caballero. Parece como si Erec hubiera conseguido profundizar en la esencia de la dama, descubriendo en ella esa bondad que hasta ahora había pasado desapercibida ante sus ojos. Su deseo va más allá de la mera relación sexual; pretende poseerla para impregnarse del componente virtuoso de su ser, tal y como demostrará en una escena posterior. En ningún momento se menciona, de manera tan reiterada, la hermosura externa del protagonista, y tal hecho denota la carencia de esa perfección interior inicial que quedará subsanada cuando, ayudado por su compañera, consiga comprender el significado de la convivencia; cuando sea capaz de encontrarse consigo mismo y termine por aceptar su parcela sensible.

\footnotetext{
${ }^{24}$ Este hecho es importante resaltarlo porque el autor, al plasmar tales vivencias por escrito, se distancia de los principios escolásticos de su tiempo que probablemente habrían tachado estos versos de obscenos y pecaminosos, ya que en ellos aparece implícito el anhelo de placer: "Los Padres, sobre todo san Jerónimo, (...) habían prevenido a los esposos: amarse demasiado ardientemente en el matrimonio es adulterio. San Agustín había expresado en tres palabras la finalidad de la unión: progenitura, fidelidad, sacramento." En: G. Duby, M. Perrot, op.cit., 269.

25 "durch Schönheit und Güte"
} 
La condescendencia, fundamental en toda relación, es uno de los rasgos configuradores de la inclinación amorosa de Enite por su esposo ${ }^{26}$. Es generosa y no recrimina a $\operatorname{Erec}^{27}$, tal es su comprensión, gracias a la cual es capaz de entender su profesión -no como la mujer de Mabonagrin, el Caballero Rojo ${ }^{28}$-. Se alegra de su éxito y comparte su triunfo, aunque continúa temiendo por su vida (v. 2826-51). Es habitual encontrar tales reflexiones y pensamientos de Enite acerca del bienestar de su compañero, pero ninguna por parte del caballero respecto a su mujer: el hombre vuelve a destacar por su conducta moderada y mesurada en lo que a amor se refiere, cuando pone en práctica sus funciones sociales. Tampoco parece ser consciente de las necesidades de su pareja -tales como la atención y la dedicación-; ni siquiera se lo cuestiona, porque concede mayor importancia al ejercicio de sus obligaciones como caballero.

El amor irracional de la dama -si bien de corte más espiritual-, visto en las primeras páginas, abandona a Enite para apoderarse del cónyuge en cuanto comienzan su vida en común. En su intimidad y apartado del mundo público, Erec actúa irracionalmente cuando se olvida del exterior para dedicarse a su mujer en cuerpo y alma. Además, el caballero comete inconscientemente un error, al comportarse de manera egoísta en sus relaciones físicas. Erec aparece en ellas como único protagonista y beneficiario: "sich vlizzen sîne sinne/wie er alle sîne sache/wante zuo gemache." (v. 2931-33)29 "sîn site er wandeln..., vertreip er..., er nider lac..., sîn meistiu arbeit..., enkam er aber nie" (v. 2934-53) 30; no afloran ni los sentimientos ni la reciprocidad que tal acto exige, convirtiéndose en una actividad individual y no compartida. Erec procede de dicha forma, porque cautivado por la personalidad de su dama, aspira a comprender su esencia y a obtener parte de ella. Una esencia caracterizada fundamentalmente por esa entrega y bondad que ha sido ofrecida al caballero, al ser Enite conocedora de las carencias en la vida de su compañero. La mujer tiene el poder de llenar el vacío del mundo, que procede, en este caso, de esa dedicación absoluta a la esfera de lo social. El exceso de la experiencia carnal está motivado por la búsqueda constante por parte del caballero, de aquello que le ofrece su esposa. Pero tal abuso conduce a la locura -traducida aquí en la desatención de las obligaciones sociales ${ }^{31}$-,

\footnotetext{
${ }^{26} \mathrm{Tal}$ y como refleja esa escena en la que consiente a su marido participar en un torneo justo después de la boda, ya que éste pretendía así seguir consolidando su prestigio. (v.2344-2363)

27 "So steht nun Enite (...) als eine mustergültige Ehefrau vor uns (...) die sich auch innerlich den Interessen des Mannes unterordnet. En: K. Smits, op.cit., 22. A este respecto dice Eva Tobler: "Enites Sanftmut, Güte und Demut sind der Grund, dass sich ihr in fast wunderbarer Weise, Leid in Liebe verkehrt. Genährt wird diese Verwandlung durch den unbeirrten Glauben an ihren Geliebten, durch die Überzeugung, dass sein Verhalten richtig ist (...) En: "Ancilla domini. Marianische Aspekte in Hartmanns Erec", Euphorion. Zeitschrift für Literaturgeschichte. Band 80, Heft 4, (1986) 434.

${ }^{28}$ Esta celosa dama va a impedir a su caballero realizarse como tal. Véase v. 9550-9561

29 "Sein Verstand richtete sich nur darauf, wie er alles zu seiner Bequemlichkeit einrichten könne."

30 "Er änderte seine Gewohnheiten..., so vertrieb er den Tag..., Morgens legte er sich nieder..., Das war seine grösste Mühe ..., von dort kam er nicht mehr weg."

31 "Indem er sein Eheleben falsch gestaltet (...) stört Erec auch das richtige Verhältnis zu den liuten und scheitert somit als Landesherr." En: K. Smits, op.cit., 16.
} 
como decían los predicadores del momento ${ }^{32}$. Lo novedoso de esta situación respecto a la mentalidad de la época, es la incapacidad que aquí experimenta el hombre (Erec) para autocontrolarse. Según los Padres de la Iglesia, al sexo masculino correspondía un amor "mesurado y temperado"; éste debía "amar con juicio" y sin dejarse llevar por los sentimientos $^{33}$. La presente obra contradice dichos tratados, haciendo ver que el ser humano se comporta de forma instintiva debido a su condición natural. Además, Enite tampoco encaja aquí con la imagen de mujer lujuriosa atribuida siempre en el Medievo al sexo femenino. En este caso la iniciativa pasional proviene del hombre, al cual los mismos tratados recomendaban, sorprendentemente, ser aleccionado por la propia mujer: "la mujer es responsable del amor (...) la mujer debe lograr imponer al amor del cónyuge la moderación que ella misma no puede. ${ }^{34}$ Pero la conducta de Erec no debe ser considerada lasciva -aunque no canaliza adecuadamente sus impulsos-, pues está cumpliendo con el principio del matrimonio que exhorta a la búsqueda del otro ${ }^{35}$. En el ámbito familiar y personal, donde el protagonista no tiene que demostrar ni su fuerza ni su valor, se perfila como un ser humano limitado que necesita de otro. Enite por su parte, ama profundamente y por eso se da, se dona, proporcionando a su compañero la mitad que le falta.

En esta vida matrimonial vuelve a irrumpir la sociedad, que pone en entredicho la actuación del protagonista. Su reacción confirma el lugar prioritario que sigue ocupando el mundo exterior en su escala de valores, al sentirse ofendido por comentarios ajenos respecto a su figura como caballero. Estos rumores turban el pensamiento de la dama, a la que le reprochan, indirectamente, su entrega y amor incondicional, además de culparla injustamente de haber ocasionado la dependencia de éste a su persona: dependencia de la que dejan constancia los siguientes versos: "Erec wente seînen lîp/grôzes gemaches durch sîn wîp./die minnete er sô sêre (...)" (v. 2966-68)36. La consecuencia inmediata que resulta del orgullo herido del protagonista, es el peregrinaje que debe realizar la pareja, y en el que Erec asiste a su propia lucha interior para reconciliarse consigo mismo y con el exterior ${ }^{37}$. $\mathrm{Su}$ vanidad le impide asimismo viajar al lado de su esposa, que le ocultó por amor su desidia para con los demás, pues temía perderlo en algún combate violento. Ella también lo necesita, no sólo la sociedad, y procura buscar en su compañero esa amistad que suponga una dedicación plena y constante por parte del caballero. Pero la amistad exige

\footnotetext{
32 "Celos, pasión y, en el extremo, locura, son las consecuencias del amor excesivo por la esposa (...)" En: G. Duby, M. Perrot, op.cit., 140.

${ }^{33}$ Véase G. Duby, M. Perrot, op.cit., 139-40.

${ }^{34}$ G. Duby, M. Perrot, op.cit., 140. Según esto, Enite parece actuar de forma errónea también, al no conseguir imponer esa mesura al amor de su marido. Porque aunque la mujer "debe hacerse amar para evitar que el marido caiga presa de la libido, para cuya contención se creó el matrimonio, no debe hacerse amar demasiado para no excitar ella misma la libido." En: ibidem.

35 "El acto, no exento de mal quedaba por lo menos exento de mal moral o pecado, mas sólo si se lo excusaba mediante los fines legítimos del matrimonio." En: J. Menéndez, Nueva visión del amor cortés. (Oviedo 1980) 130.

36 “Erec gewöhnte sich um seiner Frau willen an grosse Bequemlichkeit. Er liebte sie so sehr (...)

37 “Männlichkeit jedoch, die von der höfischen Frau gefördert werden soll, verlangt Streben und sich der Gefahr aussetzen (...) Vielmehr geht es Erec darum, sich von neuem vor der Frau, der Vertreterin der Gesellschaft und Verwalterin der höfisch-ritterlichen Ideale, zu beweisen." En: E. Carne, op.cit., 59, 60.
} 
compenetración de ideas y sentimientos, y aunque ambos desean lo mismo, sienten todavía de manera diferente, pues en Erec siguen prevaleciendo las pautas de comportamiento cortesanas que le impiden conjugar la esfera privada con la pública. Esta es la razón por la cual ordena a su dama no hablar ni cabalgar a su lado durante el viaje, para poder concentrarse en el objetivo primordial que requiere su atención: la restitución de su honor y dignidad como caballero. Está convencido del amor de Enite, pero al no comprender aún el significado de la ayuda mutua en la vida marital ${ }^{38}$, comete el error de castigarla. Es tal el amor por su compañero, que ella procurará educarlo en el principio del apoyo recíproco inmanente en la relación de pareja. Para ello hace gala de un comportamiento rebelde, arriesgándose a soportar las incomodidades impuestas por su esposo, porque su sentimiento amoroso supera al miedo y su valentía lo corrobora ${ }^{39}$. El autor parece defender la actitud de una dama ("die viel guote", v. 3278, "ein wîp unwandelbaere" v. 6791, "die tugentrîchen" v. 6795) $)^{40}$, paciente y humilde, que sufre debido a la ignorancia de su cónyuge. Ella tiene la capacidad de ver y oír los peligros que se presentan; él lucha para reducirlos. La sensibilidad, unida a la fuerza y a la constancia (lo racional) que aportan uno y otro respectivamente ${ }^{41}$, hacen posible la compenetración y el equilibrio que deben presidir la relación amorosa -idea que la dama procura hacer entender a su amado cada vez que le desobedece ${ }^{42}$, rompiendo su silencio, para advertirle de cualquier amenaza exterior-. Erec, sin embargo, insiste en acercarla al mundo de la caballería y conciliarla con éste. Por dicho motivo le corrige -cumpliendo con el imperativo medieval que asignaba la instrucción moral de la mujer al esposo que se preciara quererla-, y le intenta inculcar la obediencia que debe prestar el sexo femenino al hombre; sumisión considerada por los predicadores de aquel entonces como signo indiscutible de amor al marido ${ }^{43}$. Enite desobedece por amor, y su actuación desvaloriza, por tanto, las tesis expuestas. El carácter "díscolo" de la dama en esta escena desconcierta a Erec, "wie nû, ir wunderlîchez wîp (...)?" (v. 3238)44, porque se enfrenta a una mujer atípica y llena de sorpresas, a la cual su corazón es incapaz de corresponder. Queda demostrado que la imposición de normativas no hace entrar en razón a la mujer, sino es al final, con ternura y besos, cuando el caballero la conquista de nuevo. Haciendo caso omiso a sus numerosas promesas de guardar silencio, Enite contribuye a la transformación paulatina del protagonista. Éste comienza a expresar abiertamente sus

\footnotetext{
38 "Erec muss lernen, seine Frau zu verstehen. Er muss durch Erfahrung (...) lernen, die tiurende kraft ihrer minne (...) positiv auf sich einwirken zu lassen." En: K. Smits, op.cit., 23.

${ }^{39}$ Enite rompe el silencio que le ordenó guardar su marido -bajo amenaza de muerte- para avisarle de los peligros que le acechaban.

40 "Die Gute; eine zuverlässige Frau; die Vortreffliche".

41 “Erst aus der Verbindung von männlicher, Tüchtigkeit und Meisterschaft' mit dem rezeptiv-weiblichen Element der Natur entsteht der vollkommene Mensch.” En: E. Carne, op.cit., 11.

42 "Indem er durch die Abenteuer vorwärts schreitet, wird ihm der wahre Sinn der Liebe enthüllt, der nicht Genuss ist, sondern Selbstaufopferung." En: E. Carne, op.cit., 88.

43 "Su amor total para con el cónyuge se dirige a cumplir siempre la voluntad del marido (...) Amar a éste es someterse voluntariamente. Se exhorta a la obediencia, debido a la culpa originaria provocada por la mujer." En: G. Duby, M. Perrot, op.cit., 140 .

44 "Wie denn, seltsame Frau (...)?"
} 
sentimientos por la amada, al tiempo que ejerce sus funciones (se disponía a retarse con un caballero), tal y como indican los siguientes versos:

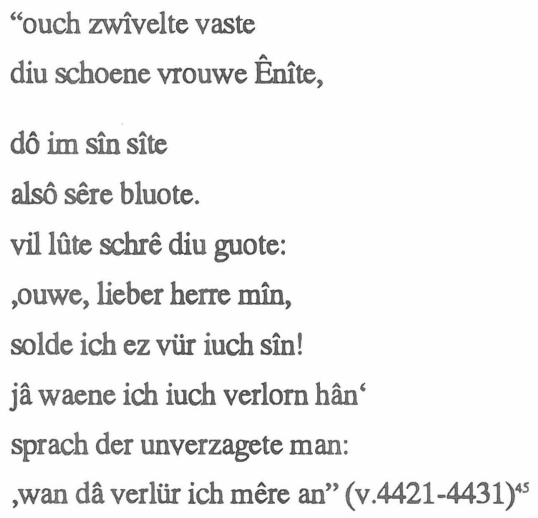

El sufrimiento que por amor soporta Enite es constante, y éste se agrava con la supuesta muerte de su compañero, hecho ante el que experimenta una profunda desesperación ( $\mathrm{v}$. 5755-5769) ${ }^{46}$, la cual hace brotar en ella el deseo de su propia aniquilación. La dama no es más que amor y cuando se le priva de su razón de ser, ésta ya no tiene sentido. Enite se transforma radicalmente por unos momentos y su espíritu sumiso da paso a una rabia nunca antes en ella contemplada, ",wê dir, vil übeler Tôt!/daz dû vervluochet sîst! (v. 5916) ${ }^{47}$, que le permite incluso enfrentarse verbalmente a Dios, "frouwe Enite zurnte vaste an got." (v. $5774)^{48}$, cuyos designios no está dispuesta a aceptar. Su total dependencia a Erec le impide entregarse a otro hombre, Oringles, y se deja magullar por éste cuando no accede a cumplir sus órdenes. Erec "resucita" (recobra el conocimiento tras el golpe recibido en un duelo con un gigante) en cuanto reconoce el lamento de su dama. Se incorpora a la vida con otras intenciones, con nuevos pensamientos, y esto explica su repentina puesta en marcha, "ûf spranc er mit grimme" (V.6615) ${ }^{49}$, reacción a través de la cual se confirma su interés por defender el amor, la intimidad y la privacidad: "er hâte zornes genuoc" (v. 6620) ${ }^{\text {so }}$. El esposo reconoce la voz de su compañera, una voz que invade su conciencia y le sirve de guía, pues le conduce hasta ella, permitiéndole además salir de esa desorientación y confusión en la que permanecía sumido (expresada con la imagen de la "muerte"-desmayo).

\footnotetext{
45 "Auch der schöne Enite kamen schwere Zweifel, als seine Seite so heftig blutete. Laut schrie die Liebliche: $>$ Ach mein lieber Herr, könnte ich es doch an Eurer Stelle sein! Ich fürchte, ich habe Euch verloren. $<>$ Herrin, Ihr irrt Euch<, sagte der Tapfere. >Denn ich würde mehr daran verlieren.<"

46 "Frauen können demnach auch im Notfall nicht ,nach männlicher Art' aktiv tätig werden. Die ihrer Natur angemessene Reaktion ist der Gefühlsausbruch." En: K. Smits, op.cit., 20.

47 "Frauen können demnach auch im Notfall nicht ,nach männlicher Art' aktiv tätig werden. Die ihrer Natur angemessene Reaktion ist der Gefühlsausbruch." En: K. Smits, op.cit., 20.

48 "Enite haderte mit Gott."

49 "sprang er grimmig auf"

so "Er war zornerfüllt;"
} 
Ésta había sido provocada por aquella incapacidad para conjugar la razón -es decir, la vida pública, sus obligaciones como caballero- con los sentimientos, esto es, su relación de pareja. Asimismo, la debilidad que se apodera del protagonista, durante unas horas, pretende hacer ver que la única forma de adquirir integridad y fortaleza individual consiste en unir ambas vertientes. Erec actúa ahora movido por el amor y la preocupación hacia su mujer y tal hecho demuestra que las penalidades soportadas con resignación por Enite (el maltrato de Oringles en este caso) han posibilitado el acercamiento de los protagonistas. Su reconciliación queda sellada metafóricamente en esa aparición conjunta a caballo, cuando tratan de huir del poderoso conde Oringles. El cabalgar en un mismo animal permite presuponer que ahora ambos personajes son dos en uno, cuya separación a corto o largo plazo será prácticamente imposible. La compenetración total de la pareja se ha conseguido por fin, tal como se deduce de esa capacidad que en estos instantes posee Erec para sentir (ver) a través de Enite, cuyos ojos enseñan a éste el camino que les debe conducir a un lugar seguro; ayuda aceptada por el amado, esta vez sin amenazas. El caballero, comprendiendo y asumiendo el papel de la mujer en la vida matrimonial de compromiso permanente, es consciente además del apoyo que deben prestarse mutuamente los partícipes de la misma::1 en una ocasión Enite muestra el sendero a su esposo y más adelante será Erec el que se percate del peligro, tal como rezan los versos 6879-80, "vrouwe, ich hoere rîten/engegen uns ein michel her"s2. Tampoco le reprende cuando ésta impide su muerte a manos del caballero Guivreiz, pudiéndose constatar una vez más, que el amor ha sido el artífice de una auténtica metamorfosis en la persona del protagonista. Éste, tras encontrar justificación al comportamiento de la dama deja al descubierto su lado más humano manifestando su arrepentimiento y su disculpa cariñosa por las difíciles situaciones a las que fue puesta a prueba su fidelidad. La transformación interior de Erec aparece recogida en uno de los pasajes más bellos de la obra (a partir del verso 8840), donde el amado expresa abiertamente y sin tapujos sus verdaderos sentimientos, siendo leal al mismo tiempo a su condición de caballero, al disponerse a tomar parte en un enfrentamiento. Esta vez, el amor ha acrecentado su vulnerabilidad porque por primera vez es víctima del miedo, "ez enwas et ritter nie/mê guntroestet dan er wart." (v.8887-88) $)^{s_{3}}$. El sentimiento amoroso posibilita asimismo la fijación de su pensamiento en Enite, reportándole esta simple acción la fortaleza necesaria para vencer, contrastando todo ello con la presencia física de la dama requerida por Erec en las primeras páginas, donde no se había alcanzado todavía la unión espiritual entre los protagonistas, la cual tiene lugar al final de la obra. La mujer, que siempre había sido vista de forma negativa ${ }^{54}$, consigue enmendar a su contrario con su

\footnotetext{
51 “Nur Enitens Aufschrei weckt Erec aus seinem Tod -nur die Hilfe Erecs rettet Enite vor ihrem Tod! Da ihnen so auf letzte Weise bestätigt ist, was Erec in allen vorangehenden Proben nicht anerkennen wollte: dass sie nur dann leben können, wenn sie auf ihre Minneverbundenheit bauen (...)" En: H. Kuhn, "Erec" En: Hartmann von Aue. H. Kuhn, C. Cormeau (eds.) (Darmstadt 1973) 33.

52 "Herrin, ich höre uns eine grosse Truppe entgegenreiten."

53 “jedenfalls war niemals ein Ritter sorgenvoller als er"

54 "The view of woman as instrument of the Devil, a thing at once inferior and evil, took shape in the earliest period of Church history (...)" En: E. Power, Medieval Women (Cambridge 1976) 15.
} 
dedicación ${ }^{55}$, para salvaguardar de este modo la convivencia. Pues como se aseguraba en el Medievo, ">la blandura < típica de la mujer (...) característica de su inferioridad, podía, en cambio convertirse en el elemento sobre el cual apoyarse para suavizar a un marido demasiado duro (...)"56 . Por ello, "el vínculo matrimonial se configura como compromiso para ayudar al esposo en todos los aspectos de la existencia"s7.

El sentimiento amoroso concede en este caso a la mujer un grado de superioridad mayor respecto al caballero, tal como refleja esa perfección que envuelve su ser y hace su presencia necesaria para servir de guía espiritual al esposo con el fin de educarlo en el amor y la sensibilidad. Su preeminencia queda igualmente constatada a través de ese profundo conocimiento que parece poseer acerca de la situación vital de su compañero. Es plenamente consciente (no así el interesado) de la carencia afectiva en la existencia de este hombre, necesitado de la protección que ofrece el núcleo conyugal frente al exterior, frente a las imposiciones de la sociedad caballeresca. Aunque el comportamiento humilde y sumiso de la dama a lo largo de la narración la relegan a un segundo plano, una lectura no tan superficial de la obra permite observar que la actuación de la mujer reviste gran importancia para la formación emocional del esposo. Su sencillez y aparente fragilidad encubren la grandeza de su esencia y su fortaleza interior respectivamente, obtenidas gracias a su capacidad de amar positiva y desinteresada que permite el desarrollo individual del cónyuge a ambos niveles. El autor revaloriza la aportación de la mujer a esta relación pues con su "martirio" incita a la "conversión", a que Erec aprenda a amar.

\footnotetext{
55 "Seine Frauengestalten (Hartmanns von Aue) erfüllen weiterhin ihre Aufgabe als Erzieherin und Inspiration des Ritters (...)" En: E. Carne, op.cit., 8. Hugo Kuhn ensalza, además, la pureza de este personaje femenino como "einer der reinsten Frauengestalten in Mittelalter und Neuzeit."En: "Erec" En: Hartmann von Aue. Kuhn, H., Cormeau, C., (eds.) (Darmstadt 1973) 48.

${ }^{56}$ G. Duby, M. Perrot, op.cit., 144.

${ }^{57}$ G. Duby, M. Perrot, op.cit., 146.
} 
